\title{
Deformation of the Nasal Septum in Children, Adolescents, and Adults in Western Pomerania Province of Poland
}

\author{
I. Teul ${ }^{1}$, W. Zbislawski ${ }^{1}$, S. Baran², F. Czerwinski ${ }^{1}$ \\ ${ }^{1}$ Departament of Anatomy, Pomeranian Medical University, Szczecin, Poland; ${ }^{2}$ Faculty of Education, Sociology and Health Sciences, \\ University of Zielona Góra, Poland
}

\begin{abstract}
Objectives: Nasal septum deformation (NSD) contributes to the occurrence of upper respiratory tract diseases in around $45-55 \%$ of Poland's population. The evaluation of frequency of occurrence and type of nasal septum deformation among randomly chosen representatives of the Szczecin and surrounding area population was the aim of this study.

Methods: NSD was assessed in 235 patients (123 male, 112 female) aged 5-60. Mladina's classification system was used for the evaluation.

Results: Deformations of nasal septum were found in $43 \%$ of the examined subjects. Type 3 of NSD dominated $(12.4 \%)$, while types 2 and 1 were found in $10.3 \%$ and $4.2 \%$ of the subjects, respectively. $9.2 \%$ of the patients showed type 5 of deformation, while types 6,4 , and 7 were found in $1.3 \%, 3.2 \%$ and $2.7 \%$ of the patients, respectively.

Conclusions: Straight nasal septum was found in females more often than in males, mostly on the left side. Associations between NSD, on one side, and age, sex, and traumas, on the other were found. NSD influenced the quality of respiration and frequency of upper respiratory tract diseases in the examined subjects.
\end{abstract}

Key words: nose, septum deformations, classification, CT

\section{INTRODUCTION}

The future nose develops from five facial processes surrounding the primary oral cavity and can be visible in the middle of the face between 3.5 and 5 week of gestation. Physiologically, the nose is the beginning of respiratory tract. It filtrates, humidifies, and heats the inspired air. Human nose is considered to be a single anatomical structure, but in fact it is composed of two independently functioning cavities separated by the nasal septum. Perfectly straight septum is a rarity and can be found in a minority of population. Phylogenetically and functionally, nasal septum is a midline structure. Man seems to be the only mammal species in which the deformation occurs. Frequency of nasal septum deformation is determined by the genetic, cultural, and environmental factors [1].

Nasal septum deformation may involve the cartilaginous or osseous part. It may be a reason of a decrease in air flow through the nose, causing ventilation and oxygen saturation impairments. A long-lasting nasal obstruction may become a cause of ischemic heart disease, hypertension, pulmonary hypertension, and is an important factor contributing to obstructive sleep apnea [2]. Ailments associated with nasal septal deformation may manifest themselves as headache (inflammatory process in paranasal sinuses), breathing impairment, dysosmia, or anosmia.

The nose and its structures during the development are subject to activity of various factors which may cause defects in its morphology and functioning. Some deformations result from perinatal injury [3, 4]. Other authors do not find any correlation between nose deformations and the type of delivery $[5,6,7]$. Longitudinal studies performed in neonates and later in the same children at age 5-6 and 8 indicate that septum deformations may increase, but it never decreases [8]. It is undoubted that the final shape of the nasal septum is a result of complicated and irregular evolution of nasomaxillary mass and that it is most influenced by traumas $[9,10,11,12]$.

The aim of the present study was to evaluate the frequency of occurrence and type of nasal septum deformation among randomly chosen representatives of the Szczecin and surrounding area population.

\section{Material AND Methods}

The evaluation of nasal cavity structure with particular emphasis on the nasal septum was performed in randomly chosen citizens of Szczecin and suburbs, reporting to Szczecin's hospitals for X-ray examinations of sinuses or other areas of the head. 235 subjects were included into this study - 123 males (52.3\%) and 112 females (47.5\%) - aged 5-60 years. The population sample was stratified into 6 groups according to age as shown in Table 1.

Table 1. Sex and age in the studied age-groups.

\begin{tabular}{lcccc}
\hline & Age Group & Male & Female & Total \\
\hline Group I & Infant I (5-7 yr) & 22 & 20 & 42 \\
Group II & Infant II (8-14 yr) & 33 & 21 & 54 \\
Group III & Juvenial (15-22 yr) & 31 & 26 & 57 \\
Group IV & Adult I (23-35 yr) & 27 & 16 & 43 \\
Group V & Adult II (36-45 yr) & 7 & 17 & 24 \\
Group VI & Adult III (>45 yr) & 3 & 12 & 15 \\
& Total & 123 & 112 & 235 \\
\hline
\end{tabular}




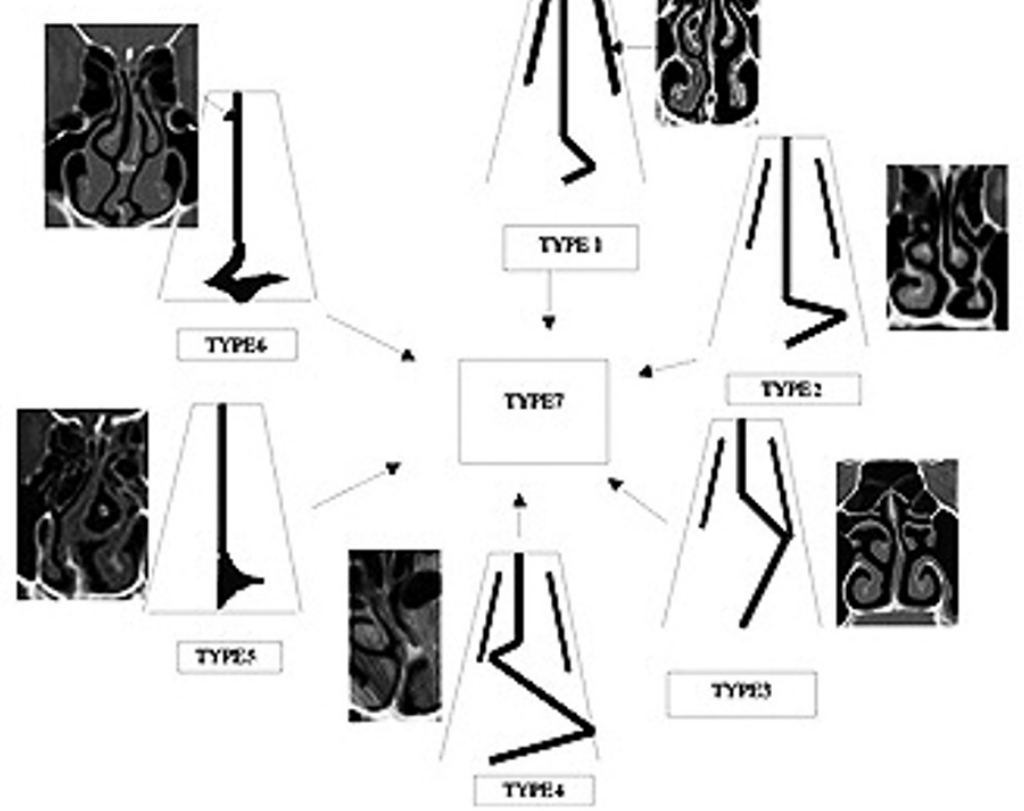

Fig. 1. Graphically presented Mladina's classification of the septum deformities. The first four types are presented from the anteriorposterior view. Type 7 presents a combination of the previous six types (modified from [11]).

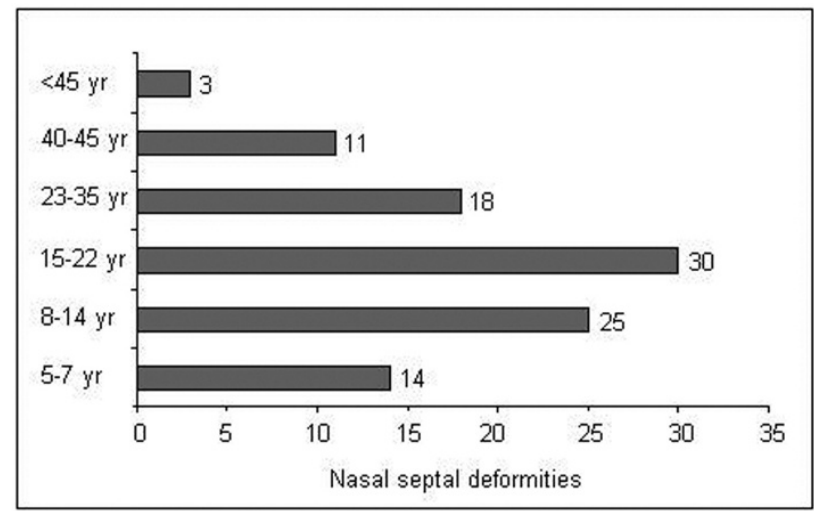

Fig. 2. Incidence of nasal septum deformation in individual age-groups.

Additionally, a questionnaire survey regarding possible causes of deformation (type of delivery, traumas, and diseases) and respiratory dysfunctions, ailments, and laryngological treatment was performed. CT scans were performed in $5 \mathrm{~mm}$ sequences from the tip of anterior nasal spine to the root of posterior nasal spine.
Nasal septum was visible on every scan and could be used as a reference and orientation point in particular scans. The nasal septum was evaluated on the basis of CT scans and its deformation was assessed according to the 7-degree Mladina classification (Fig. 1).

\section{RESULTS}

Nasal septum deformation was diagnosed in 101 persons $(43 \%$ of the evaluated subjects). Most of the deformations were found in the 15-22 (30\%) and in 8-14 (18\%) years' age-groups (Fig. 2). Males were more often affected than females (25 and 14\%, respectively) (Table 2). The frequency of nasal septum deformation increases up to the age 22 and decreases thereafter. A significant correlation was found between the age of patients and the frequency of NSD ( $F=2.35$, $\mathrm{P}=0.0003)$.

The types of deformation were variable and showed different frequency in age-groups. Deformations were more often observed in the left $(49.6 \%)$ than right side $(48.4 \%)$. In the groups I and II, type 1 $(10.3 \%)$ and type $2(4.2 \%)$ deformations predominated. Among the adults, type $3(9.1 \%)$ and posterior de-

Table 2. Frequency of NSD (\%) in relation to age and sex in the studied age-groups.

\begin{tabular}{llcc}
\hline Age Group & & Male & NSD \\
& & & Female \\
\hline Group I & Infants I $(5-7 \mathrm{yr})$ & $5(21.4 \%)$ & $10(18.5 \%)$ \\
Group II & Infant II $(8-14 \mathrm{yr})$ & $15(27.7 \%)$ & $11(10.9 \%)$ \\
Group III & Juvenial $(15-22 \mathrm{yr})$ & $19(33.3 \%)$ & $7(6.9 \%)$ \\
Group IV & Adult I $(23-35 \mathrm{yr})$ & $11(25.6 \%)$ & $5(20.8 \%)$ \\
Group V & Adult II $(36-45 \mathrm{yr})$ & $6(25.0 \%)$ & $1(1.0 \%)$ \\
Group VI & Adult III $(>45 \mathrm{yr})$ & $2(2.0 \%)$ & \\
\hline
\end{tabular}


Table 3. Frequency (\%) of types of nasal septum deformation in relation to age group.

\begin{tabular}{lcccccccc}
\hline Type of NSD* & Group I & Group II & Group III & Group IV & Group V & Group VI & Group VII & Total\% \\
\hline Type 1 & 3.38 & 2.51 & 1.21 & 1.03 & 0.98 & 0.51 & 0.68 & 10.3 \\
Type 2 & 2.21 & 1.03 & 0.5 & 0.21 & 0.21 & 0.12 & 0.0 & 4.2 \\
Type 3 & 0.35 & 0.91 & 5.38 & 4.2 & 0.98 & 0.58 & 0.03 & 12.4 \\
Type 4 & 0.0 & 0.0 & 0.8 & 1.02 & 1.18 & 0.00 & 0.15 & 3.2 \\
Type 5 & 0.0 & 0.0 & 0.5 & 4.53 & 3.21 & 0.96 & 0.0 & 9.2 \\
Type 6 & 0.0 & 0.0 & 0.0 & 0.51 & 0.53 & 0.26 & 0.0 & 1.3 \\
Type 7 & 0.0 & 0.0 & 0.2 & 1.13 & 0.25 & 0.5 & 0.62 & 2.7 \\
\hline
\end{tabular}

*According to criteria described in [11]

Table 4. Comparison of incidence of nasal septum deformation between varying groups from various locations (\%).

Type of NSD Europe [14] Warsaw [23] $\quad$ Zagreb [20] $\quad$ Korea [9] $\quad$ Szczecin

\begin{tabular}{lccccc}
\hline Type 1 & 16.2 & 9.66 & 14.7 & 11.36 & 10.3 \\
Type 2 & 16.4 & 1.61 & 6.8 & 4.90 & 4.2 \\
Type 3 & 20.4 & 8.28 & 1.4 & 1.62 & 12.4 \\
Type 4 & 8.7 & 2.99 & 0.2 & 1.02 & 3.15 \\
Type 5 & 14 & 11.95 & 2.9 & 1.57 & 9.2 \\
Type 6 & 9.4 & 1.61 & 2.6 & 0.73 & 1.3 \\
Type 7 & 4.1 & 3.22 & 0.2 & 1.18 & 2.7
\end{tabular}

formation were most often observed. Type 5 was quite common in adults as well. In the studied groups, types $4,5,6$, and 7 were not observed in children (Table 3).

A comparison of the present results with those of other similar studies performed in children in Europe, Poland, Croatia, and Korea is shown in Table 4.

The questionnaire we used in the present study showed that 208 persons $(88.5 \%)$ were born in a natural manner, without complications. No massive nose trauma was indicated. NSD was observed in 78 persons $(37.5 \%)$ in this group. In the group of 27 subjects $(11.5 \%)$ born by caesarean section, who did not have any massive nose trauma in the following years, NSD was diagnosed in 5 persons (5\%). Twenty seven persons (10 men, 9 boys, 4 girls, and 5 women) indicated a nose trauma due to a fall, sporting activity, or traffic accident. Three adults were diagnosed with type 7 NSD (2.7\% of all deformations of that type) after a nose trauma. Four men were diagnosed with type 5 and another 3 with type 3 NSD. Seven boys, after a trauma, had type 5 and 2 had type 3 NSD. Two women had type 7 , while 5 had type 5 NSD. Two girls had type 5 and type 7 , while two other had type 3 NSD. All of these persons indicated trouble in breathing through the nose, especially after physical activity, and frequent nasal infections. All men having NSD after trauma indicated snoring. A significant correlation was found between the type of nasal septum deformation and nose trauma $(\mathrm{F}=3.57, \mathrm{P}=0.0008)$.

Paranasal sinuses diseases, snoring, breathing dysfunctions, and other diseases (asthma, allergies) were more often found in subjects with type 3,5, and 7 NSD. Ten persons had parents or grandparents with nasal septum defects (more often among males).
Straight septum was found in $13.4 \%$ of females and $6.5 \%$ of males.

\section{Discussion}

NSD contributes to the pathogenesis of various upper respiratory tract diseases in $45-55 \%$ of Poland's population. Grey [13] examined 2112 skulls of adult people and found that only $21 \%$ had a straight nasal septum. This imperfection of nasal cavity structure may be caused by genetic, cultural, and environmental factors. All three determinants contribute to variable distribution of particular NSD types in various ethnic groups [14]. A study performed in 17 laryngological centers in 14 countries showed that nearly $90 \%$ of examined subjects showed at least 1 of the 7 types of nasal septum deformation. There was no correlation found between the incidence of any particular type of deformation and any particular region of the world [15]. The incidence of nasal deformities in newborns has been reported to vary from $1.45 \%$ to $6.3 \%$ [16]. Grey [17] and Sorri et al [18] have stated that a neonatal mid-septal deformity will not straighten spontaneously, while caudal deformations have a high spontaneous healing rate.

Grey [19] has also argued that most deformities will become worse with subsequent growth of the nose. Contrary to several studies on the prevalence of newborn septal deformations, there are only few reports concerning the occurrence of septal deformities in older children.

The Szczecin population studies indicate septal deformations in over $40 \%$ of persons. Most NSD cases were observed in children, adolescents, and young adults $(29.8 \%)$, similarly to Zagreb's children and ado- 
lescents $(28.9 \%)$ [20], while in a similar age group of the Warsaw population they were found in $40 \%$ of subjects. Results of the Szczecin population study are about 30\% lower than those of the Warsaw population, which shows high variability in the incidence of NSD even in the same country. Finnish studies [21] showed the NSD incidence on the level of $42.9 \%$ of subjects aged 6-15, while in similar Korean population the incidence was around $22 \%$ [9]. There are differences in the incidence of particular types of NSD. In the Polish population, type 3 and 5 predominate [23]. Among Croatians and Koreans type 1 predominates (Table 4).

A decrease in the prevalence of type 1 NSD with age has been observed in Polish and Croatian populations. Observations of changes of Mladina's NSD types with age indicate that the septum deformation increases along with the growth of nasomaxillary mass and as a result of trauma. From the mild type 1, this according to our survey does not affect breathing, NSD progresses to types $2,3,5$, or 7 . NSD types 1,2 , 3,5 , and 7 are more frequent in older children and adolescents compared with the youngest children group. The incidence of type 1 deformation decreases with age, while that of types 2,3 , and 5 increase, especially in group 3 (15-22 years). Similar correlations were found in the Warsaw population, but type 5 was most prevalent there. Posterior deformations (type 3, 4,5 ) were more frequent, according to CT scans, compared with the Croatian population, where anterior deformations were 5 times more frequent [20]. Anterior deformations are thought to be a result of trauma, while posterior ones are genetically determined and associated with the growth of nasomaxillary mass. Therefore, we assume that the growth of nasomaxillary mass influences the shape of nasal septum in the Szczecin population. Similar results were obtained in Croatian studies [20]. Differences in NSD incidence in boys and girls are thought to be a result of higher physical activity of boys and resulting increased trauma risk, but in Mladina et al's studies the NSD frequency was higher in girls than in boys [14].

The present study confirms that NSD is a frequent malformation of human nasal cavity. NSD contributes to a decrease in the quality of life and plays an important role in upper respiratory tract diseases. We summarize that (i) nasal septum deformations of type 3 is most frequently observed and its incidence increases with age; (ii) incidence of type 1 decreases with age, while those of type 3 and type 5 increase; (iii) straight septum is more often found in females than males; and (iv) septum deformations prevail in boys. The risk of nasal septum deformations increases after traumas in early stages of ontogenesis.

Conflicts of interest: No conflicts of interest were reported by the authors in relation to this article.

\section{REFERENCES}

[1] Takahashi R. The formation of nasal septum deformation in human evolution. Rhinology 1977; 15: 12-20.

[2] Dart RA, Gregoire JR, Gutterman DD, Woolf SH. The association of hypertension and secondary cardiovascular disease with sleep-disordered breathing. Chest 2003; 123: 244-260.
[3] Grey L. The development and significance of septal and dental deformity from birth to eight years. Int J Pediatr Otorhinolaryngol 1983; 6: 265-277.

[4] Alpini D, Corti A, Bursa E, Bini A. Septal deformation in newborn infants. Int J Pediatr Otorhinolaryngol 1986; 11: 103-107.

[5] Quante M, Franzen G, Strauss P. The correlation between permanent septal deformities and nasal trauma during birth. Rhinology 1976; 16: 141-146

[6] Stoksted P, Schønsted-Madsen U. Traumatology of the newborn's nose. Rhinology 1977; 17: 77-82

[7] Korantzis A, Cardamakis E, Cheliodonis E, Papamihalis T. Nasal septum deformity in the newborn infant during labour. Eur J Obstet Gynecol Reprod Biol 1992; 44: 41-46.

[8] Grey LP. Prevention and treatment of septal deformity in infancy and childhood. Rhinology 1977; 15: 183-191.

[9] Bhargava I, Sharma J.C. The nose in relation to head and face. An anthropometric study. J Otolaryng 1959; 11: 1-6.

[10] Grymer LP, Pallisgaard C. Melsen B. The nasal septum in relation to the development of the nasomaxillary complex: A study in identical twins. Laryngoscope 1991; 101: 863-868.

[11] Mladina R, Bastaic L. What do we know about septal deformities? J Rhinol 1997; 2: 79-89.

[12] Haapaniemi JJ, Suonpää JT, Salmivalli AJ, Tuominen J. Prevalence of nasal deformations in school-aged children. Rhinology 1995; 33: 1-3.

[13] Grey LP. Deviated nasal septum. Incidence and etiology. Ann Otol Rhinol Laryngol 1978; Suppl 50: 1-20.

[14] Mladina R, Cujic E, Subaric M, Vukovic K. Nasal septal deformities in ear, nose, and throat patients: an international study. Am J Otolaryngol 2008; 29: 75-82.

[15] Jeppesen F, Windfeld I. Dislocation of the nasal septal cartilage in the newborn. Acta Obstet Gynec Scand 1972; 51: 5-15.

[16] Kent SE, Reid ER, Nairn DJ. Neonatal septal deformations. J R Soc Med 1988; 81: 132-135.

[17] Grey LP. Relationship of septal deformity to snuffly nose, poor feeding, sticky eyes and blocked naso-lacrimal ducts. Int J Pediat Otorhinolaryngol 1980; 2: 201-215.

[18] Sorri M, Laitakari K, Vainio-Mattila J, Hartikainen-Sorri AL. Immediate correction of congenital nasal deformities; follow-up of 8 years. Int J Pediatr Otorhinolaryngol 1990; 19: 277-283.

[19] Grey LP. Septal and associated cranial birth deformities, types, incidence and treatment. Med J Aust 1974; 1: $557-$ 563.

[20] Subaric M, Mladina R. Nasal septum deformities in children and adolescents: a cross sectional study of children from Zagreb, Croatia. Int J Pediatr Otorhinolaryngol 2002; 63: 41-48.

[21] Hartikainen-Sorri AL, Sorri M, Vainio-Mattila J, Ojala K. Etiology and detection of congenital nasal deformities. Int J Pediatr Otorhinolaryngol 1983; 6: 83-88.

[22] Grymer LF, Bosch C The nasal septum and development of the midface. A longitudinal study of a pair of monozygotic twins. Rhinology 1997; 35: 6-10.

[23] Olszewska O, Zielnik-Jurkiewicz B, Chmielnik M, et al. Ocena wystepowania typów skrzywien przegrody nosa u dzieci i mlodziezy. Otorynolaryngologia 2003; 2: 79-82 (Article in Polish).

Author's address:

Teul M. D.

Pomeranian Medical University

Department of Anatomy

Powstancow Wielkopolskich 72 St.

70-111 Szczecin, Poland

Phone: +48914661480

E-mail: Teul@life.pl 